\title{
Measles virus genotyping an important tool in measles outbreak investigation in Norway, 2011
}

K Vainio (kirsti.vainio@fhi.no) ${ }^{1}$, T W Steen ${ }^{2}$, T M Arnesen³, K Rønning ${ }^{4}$, G Ånestad ${ }^{1}$, S Dudman ${ }^{1}$

1. Norwegian Institute of Public Health, Department of Virology, Oslo, Norway

2. Health and Welfare Authority, City of Oslo, Norway

3. District of old Oslo, City of Oslo, Norway

4. Norwegian Institute of Public Health, Department of Infectious Disease Epidemiology, Oslo, Norway

Vainio K, Steen TW, Arnesen TM, Rønning K, Ånestad G, Dudman S. Measles virus genotyping an important tool in measles outbreak investigation in Norway, 2011. Euro Surveill. 2012;17(50):pii=20340. Available online: http://www.eurosurveillance.org/ViewArticle.aspx?Articleld=20340

This study describes 33 laboratory-confirmed cases of measles that occurred in Norway in 2011, mainly among unvaccinated children between seven months and 10 years of age. Laboratory testing included detection of anti-measles IgM- and IgG antibodies by enzyme-linked immunosorbent assay (ELISA) and molecular detection and characterisation of measles virus by polymerase chain reaction (PCR) and sequencing. Epidemiological data and genotyping revealed that the measles cases originated from eight separate importations, resulting in four outbreaks and four sporadic cases. Except for the first outbreak which affected 18 cases, limited secondary spread occurred in each of the three other outbreaks. The outbreaks were caused by measles virus genotypes $B_{3}, D_{4}$ and D9, whereas genotypes $D 8$ and $B_{3}$ were detected in the sporadic cases. This study highlights that genetic characterisation of measles virus is an essential tool in the laboratory surveillance of measles, especially in countries like Norway which are approaching the measles elimination goal. The investigation revealed that importation of measles resulted in subsequent transmission within Norway to non-vaccinated individuals, and twelve cases occurred in healthcare settings, involving both staff and children. The four cases detected among healthcare workers (HCWs) emphasised that the coverage of measles-mumps-rubella (MMR) vaccination among healthcare personnel needs to be improved and both primary and secondary vaccine failure was demonstrated in two fully immunised HCWs.

\section{Introduction}

Measles, a highly contagious respiratory viral disease characterised by the appearance of fever and a rash, is the leading cause of vaccine-preventable childhood mortality worldwide [1]. The incubation time is between 10 and 14 days, and a measles infected person is contagious from four days before to four days after the rash appears. Although a safe and cost-effective vaccine has been available for decades, measles is still an ongoing public health problem in several European countries.
Between January and October 2011, 26,074 measles cases were reported in the World Health Organization (WHO) European region [2]. The target date for elimination of measles in Europe has been changed a number of times, and due to widespread outbreaks occurring in both eastern and western Europe (Austria, Bulgaria, France, Germany, Romania, Switzerland, and the United Kingdom (UK)) [3] the WHO Regional Office for Europe most recently (2010) changed the target date from 2010 to $2015[3,4]$.

Measles elimination is defined as the interruption of indigenous transmission of measles virus for a 12-month period [5]. In order to prevent outbreaks, a measles vaccine coverage of $95 \%$ for two doses of vaccine is needed [6]. In addition, strong national surveillance systems are necessary to detect all clinical cases of measles and to investigate thoroughly all single cases and outbreaks. In Europe, personal attitudes toward vaccination are factors that influence the vaccination coverage, which is variable [3].

Laboratory diagnosis is required for confirmation of measles, especially in times of low incidence, when most cases of fever illness with rash are caused by other agents. The WHO currently recognises eight clades of measles virus $(\mathrm{A}-\mathrm{H})$ with a total of 23 genotypes recognised within the clades, and viruses with related sequences within a genotype (e.g. B3) are referred to as clusters $[7,8]$. Molecular characterisation of measles virus isolates is vital in outbreak investigations and the only tool that demonstrates the interruption of circulating endemic virus $[5,9]$. Consequently, it is one of the key components of the verification of measles elimination.

In Norway, measles is a mandatory notifiable disease. Between 1975 and 1988 only measles encephalitis cases were notified, but since 1988 all cases of measles are notifiable. All children residing in Norway are offered the measles vaccine free of charge as part of the childhood vaccination programme. One dose of 
a monovalent measles vaccine was introduced in the national vaccination programme in Norway in 1969. This was replaced by the combined measles-mumpsrubella MMR vaccine in 1983, applied in a two-dose schedule (at 15 months and at 11-12 years of age). Due to a high coverage ( $>90 \%$ ) of two doses of the MMR vaccine in the last decades, according to the National vaccine register (SYSVAK) [10], measles incidence has declined in Norway since first half of the 1980 s $[11,12]$. In 2011, the vaccination coverage in two year-olds (birth cohort 2009) with the first dose was 93\% in the whole of Norway, $92 \%$ in Oslo and $88 \%$ in the district of Old Oslo in Oslo [10]. The MMR vaccine coverage data for the second dose is available for 16 year-olds (birth cohort 1993) and the coverage was 90\% in the district of Old Oslo and $94 \%$ in Oslo as well as in rest of the country [10]. All measles cases identified during the last decade in Norway have been linked to importation from endemic areas or linked to other outbreaks in Europe $[12,13]$. The last outbreak in Norway before 2011 occurred in 2008 in an anthroposophical community, where the index case fell ill after returning from Austria [14]. In 2007, there was an outbreak among members of the Irish travelling community from England who were in Norway at the time [13]. Measles spread among unvaccinated children within the community, but no cases occurred in the local population.

The present study describes epidemiological and molecular data from measles outbreaks and sporadic cases detected in Norway during 2011. Preliminary data from the first outbreak has been published previously [15].

\section{Methods}

Samples and epidemiological data

Case-based surveillance of measles is conducted continuously in Norway. The case definition used in the present study was based on the WHO classification of measles cases [16]. In Norway, the WHO National Reference Laboratory for Measles and Rubella is located at the Norwegian Institute of Public Health (NIPH) where samples obtained from suspected and notified measles cases are routinely sent for confirmation. All laboratory-confirmed cases are reported to the surveillance system. Healthcare personnel who suspect a measles case are required to notify the NIPH via the institute's 24-hour call centre, and then send the samples directly to the NIPH reference laboratory to be analysed immediately to expedite the public health response. Thirty-three notified cases in Norway in 2011 were investigated at the NIPH. The information during the case investigation was collected by telephone interview and included demographic characteristics, ethnic background, clinical symptoms, hospitalisation, vaccination status, travel history and laboratory data. Contact tracing is also routinely undertaken, especially for unvaccinated and exposed individuals.
Laboratory analysis

All samples (serum and oral fluid) were initially tested for the presence of anti-measles IgM- and IgG antibodies with commercially available IgG- and IgM enzymelinked immunosorbent assays (ELISA) (Enzygnost ELISA, Siemens Healthcare Diagnostics Products, Marburg, Germany) and/or measles IgM capture enzyme immunoassay (EIA) (Microimmune Ltd, Middlesex, UK). The assays were performed as recommended by the manufacturer and assay results on the samples were interpreted qualitatively as positive, negative or equivocal. Measles infection was confirmed when anti-measles IgM antibodies were present. In the event of an equivocal result, a second serum or oral fluid was requested to ascertain seroconversion. Measles IgG avidity testing was performed at the WHO Regional Reference Laboratory (RRL) for measles, at the Robert KochInstitute in Berlin, using anti-measles virus ELISA (IgG) assay (Euroimmun AG, Luebeck, Germany). Avidity ratios $<40 \%$ were considered to be low, $>40 \%$ and $<$ $60 \%$ to be borderline and $>65 \%$ to be high.

Viral RNA was extracted from the clinical samples using the QIAamp viral RNA mini kit (Qiagen, Germany). RNA was converted to complementary DNA (cDNA), and nested polymerase chain reaction (PCR) was performed using primers amplifying a 450-nucleotide (nt) fragment encoding the $\mathrm{C}$-terminal end of the nucleoprotein $(\mathrm{N})$ [17]. All PCR positive samples were sequenced according to the WHO recommendation. Sequences were aligned by Clustal W [18], and phylogenetic and molecular analyses were performed using Molecular Evolutionary Genetics Analysis (MEGA) version 5.0 software [19]. A phylogenetic tree was constructed by using the maximum likelihood method. Genotype assignment was performed by sequence comparison with the measles virus reference strains as designated by WHO $[20,21]$.

Sequences from the Norwegian isolates have been deposited in the GenBank database or the measles nucleotide surveillance (MeaNS) database [22] and the GenBank accession numbers are: JN599049-JN599064 and JX680814-JX680820. Measles virus sequences included in the phylogenetic tree are WHO reference strains, genotype $B_{3}$ variant strains (MVs/Minnesota. USA/10.11/2, MVs/Minnesota.USA/12.11/ and Pretoria. ZAF/13.09/1 (personal communication, Sheilagh Smit, 12 May 2011) and the sequences from the Norwegian isolates.

\section{Outbreak definition}

In countries with an elimination goal (e.g. Norway), a measles outbreak is defined as two or more confirmed cases that are temporally related and linked epidemiologically and by detection of the same virus variant. Cases with disease onset within 18 days and who could be epidemiologically linked (e.g. same emergency unit, household, community, kindergarten) were grouped into the same outbreak. Molecular typing of measles 


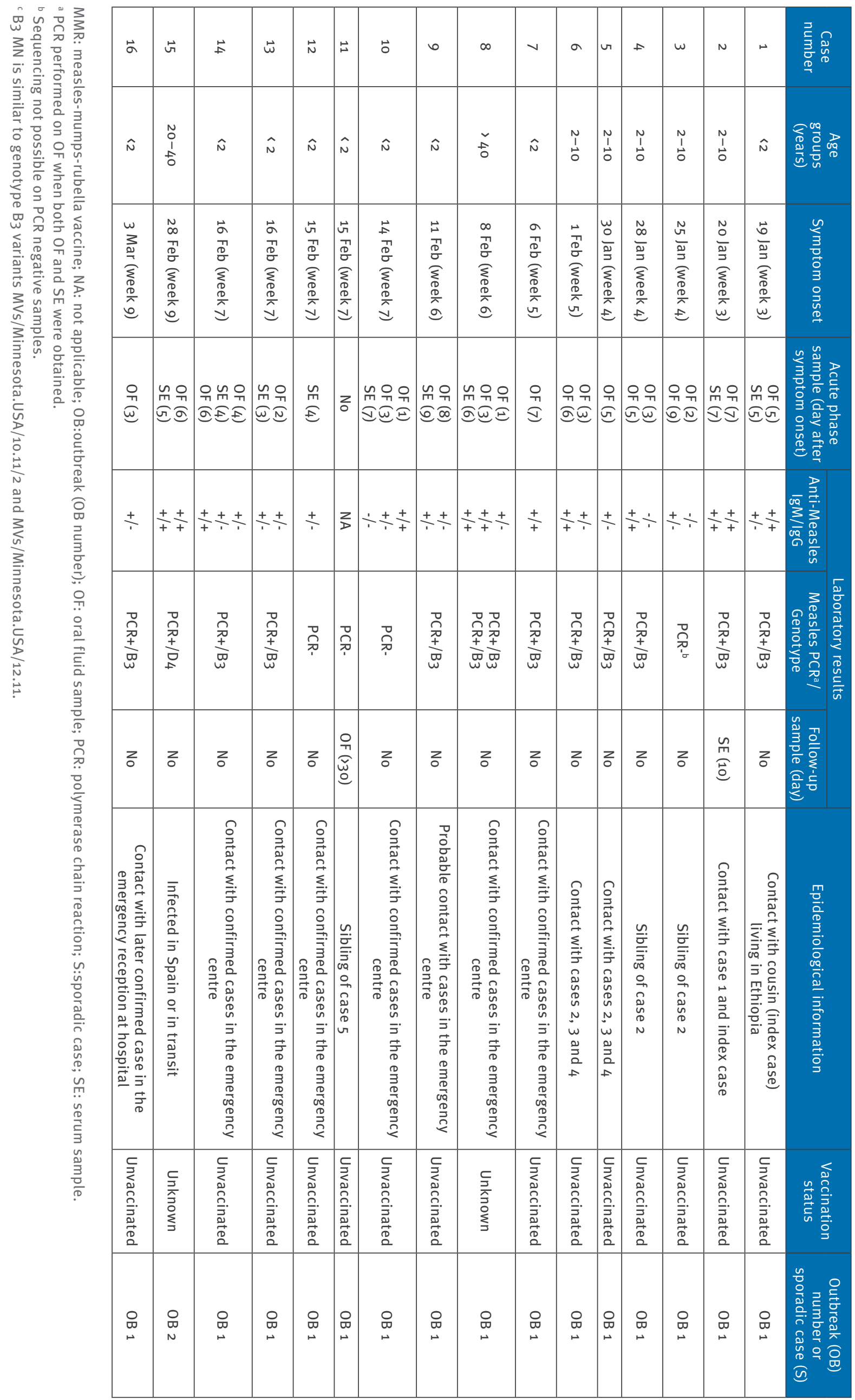




\begin{tabular}{|c|c|c|c|c|c|c|c|c|c|c|c|c|c|c|c|c|c|c|}
\hline 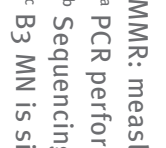 & $\stackrel{\omega}{\omega}$ & $\underset{N}{w}$ & $\underset{\uplus}{\omega}$ & w & $\tilde{N}$ & $\mathbb{\infty}_{\infty}$ & 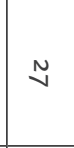 & $\stackrel{N}{\sigma}$ & N & $\stackrel{N}{f}$ & $\stackrel{\sim}{\omega}$ & $\mathbb{N}$ & N & N & $\vec{b}$ & $\vec{\infty}$ & $\vec{v}$ & 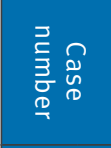 \\
\hline 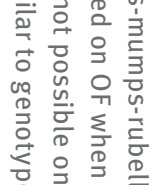 & $\begin{array}{l}\text { No } \\
i \\
0 \\
0\end{array}$ & $\mid \begin{array}{l}n \\
\tilde{1} \\
\stackrel{0}{*}\end{array}$ & $\hat{N}$ & \begin{tabular}{|l|} 
\\
1 \\
0
\end{tabular} & $\hat{N}$ & $\hat{N}$ & $\begin{array}{l}\overrightarrow{0} \\
i \\
\tilde{N}\end{array}$ & $\begin{array}{l}n \\
0 \\
1 \\
0\end{array}$ & $\begin{array}{l}N \\
0 \\
i \\
0 \\
0\end{array}$ & $\begin{array}{l}\text { N } \\
\stackrel{\Delta}{L}\end{array}$ & $\hat{N}$ & $\mid \begin{array}{l}\tilde{1} \\
\stackrel{1}{o}\end{array}$ & $\hat{N}$ & $\begin{array}{l}\text { No } \\
1 \\
\text { to }\end{array}$ & $\begin{array}{l}\text { No } \\
1 \\
\text { t }\end{array}$ & $\hat{N}$ & $\begin{array}{l}\text { No } \\
1 \\
\text { to }\end{array}$ & 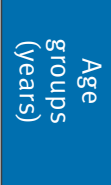 \\
\hline 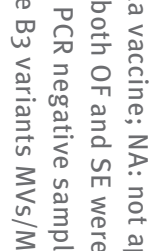 & $\begin{array}{l}u \\
0 \\
0 \\
\sum_{0} \\
0 \\
\frac{0}{\hat{\lambda}} \\
\text { a }\end{array}$ & 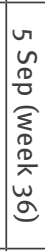 & 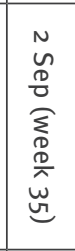 & 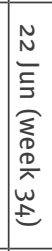 & 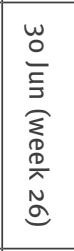 & 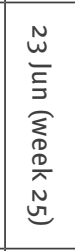 & 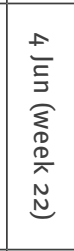 & 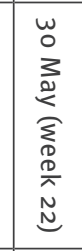 & 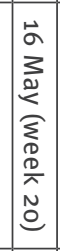 & 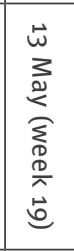 & 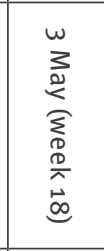 & 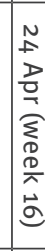 & 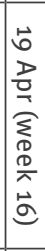 & 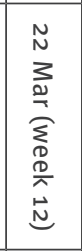 & 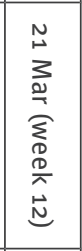 & 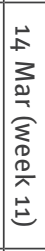 & 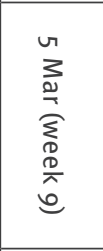 & 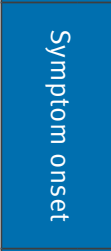 \\
\hline 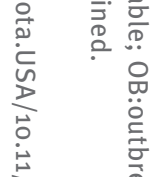 & 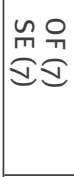 & 윹 & 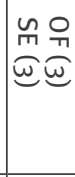 & 율 & 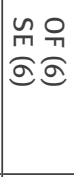 & 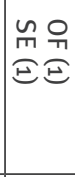 & 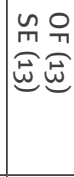 & 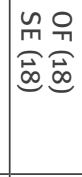 & 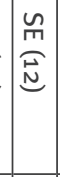 & $\begin{array}{l}\text { n } \\
\text { 监 }\end{array}$ & 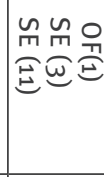 & 유 & 윰 & 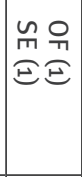 & 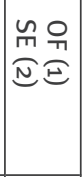 & $\begin{array}{l}\text { 유 } \\
\text { in }\end{array}$ & $\begin{array}{l}\text { 㔯유 } \\
\text { 需 }\end{array}$ & 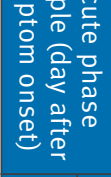 \\
\hline 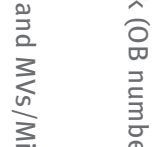 & \pm \pm & $\div$ & $\frac{+}{f}+\frac{+}{+}$ & $\stackrel{t}{t}$ & $\frac{t}{+}+\frac{t}{+}$ & \pm \pm & $\frac{t}{+}+$ & $\frac{+}{+}+$ & $\frac{t}{+}$ & \pm \pm & $\frac{+}{+} \pm \div$ & \pm & \pm & $\div \frac{+}{+}$ & $\frac{+}{+}+$ & $\frac{t}{f}$ & $\frac{t}{+}+$ & $\mid$ \\
\hline 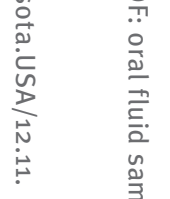 & $\begin{array}{l}\text { D } \\
\text { D } \\
\text { W } \\
\text { w } \\
\frac{3}{2}\end{array}$ & 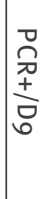 & 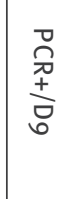 & 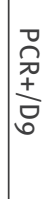 & $\begin{array}{l}\stackrel{0}{D} \\
\stackrel{+}{+} \\
\stackrel{\infty}{\infty}\end{array}$ & 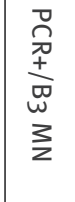 & 夙 & 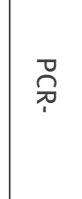 & 员 & 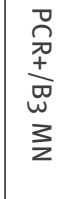 & 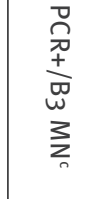 & 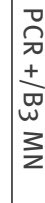 & 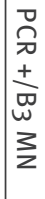 & $\begin{array}{l}\stackrel{D}{D} \\
\stackrel{D}{+} \\
\stackrel{\Phi}{\omega}\end{array}$ & గ্ৰ & 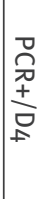 & $\begin{array}{l}\stackrel{D}{D} \\
\stackrel{+}{+} \\
\stackrel{W}{\omega}\end{array}$ & 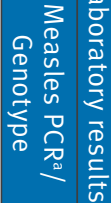 \\
\hline $\begin{array}{l}\stackrel{0}{0} \\
\stackrel{0}{0} \\
\ddot{0} \\
\stackrel{0}{\zeta}\end{array}$ & z & z & $z$ & $z$ & z & z & z & z & $z$ & $z$ & $z$ & z & z & 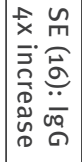 & 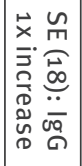 & z & $z$ & 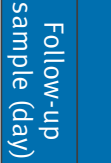 \\
\hline 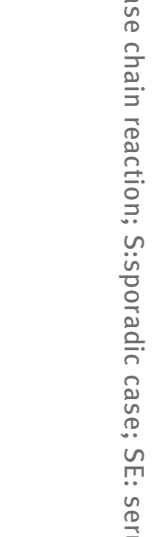 & 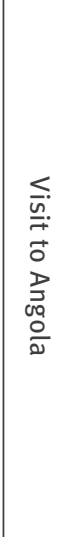 & 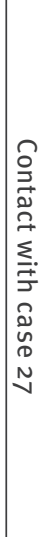 & 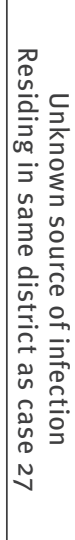 & 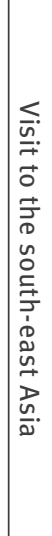 & 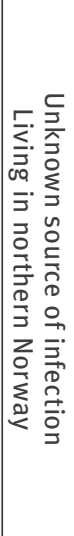 & 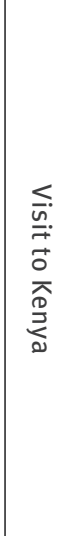 & 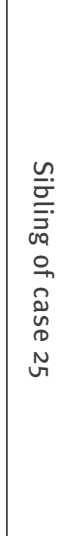 & 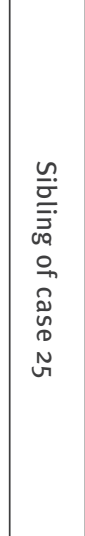 & 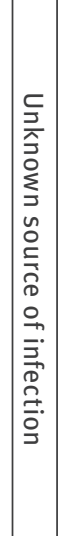 & 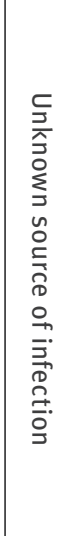 & 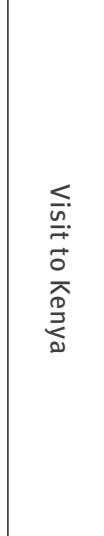 & 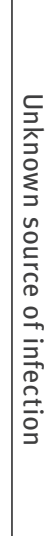 & 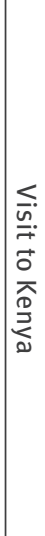 & 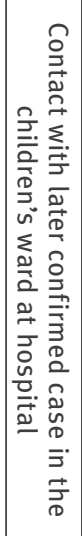 & 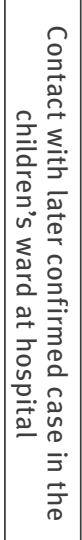 & 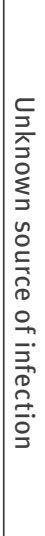 & 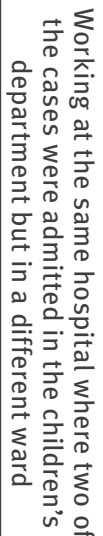 & 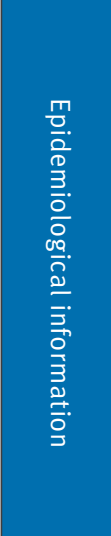 \\
\hline$\frac{3}{\frac{3}{0}}$ & 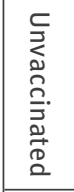 & 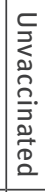 & 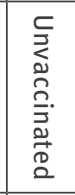 & 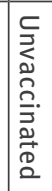 & 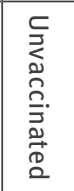 & 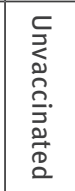 & 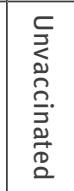 & 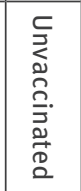 & 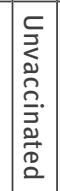 & 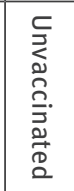 & 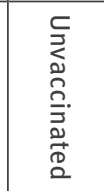 & 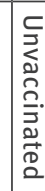 & 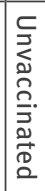 & $\begin{array}{l}n \\
3 \\
3 \\
3 \\
0 \\
0 \\
0 \\
0 \\
0 \\
0 \\
0\end{array}$ & $\begin{array}{l}\text { N } \\
\sum_{3} \\
\text { ग } \\
0 \\
0 \\
0 \\
0 \\
n\end{array}$ & 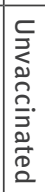 & 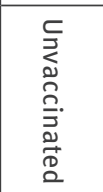 & 号 \\
\hline & $n$ & $\begin{array}{l}\text { 吕 } \\
\text { f }\end{array}$ & $\begin{array}{l}\stackrel{\circ}{\square} \\
+\end{array}$ & $\begin{array}{l}\text { 吕 } \\
-\end{array}$ & $n$ & $u$ & 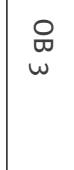 & $\underset{\omega}{\stackrel{0}{\Phi}}$ & 惫 & $\underset{\omega}{\stackrel{\rho}{\mathbf{m}}}$ & n & 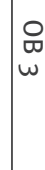 & $\begin{array}{c}\text { 吕 } \\
\text { w }\end{array}$ & 㽞 & $\underset{\sim}{\stackrel{\circ}{\square}}$ & 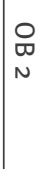 & 吕 & 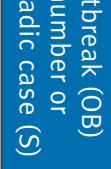 \\
\hline
\end{tabular}


virus isolates was used to differentiate simultaneously occurring outbreaks.

\section{Results}

A total of 39 measles cases were reported to the Norwegian Surveillance System for Communicable Diseases [12] during 2011, and 33 of these were investigated at NIPH (Table).

Clinical, epidemiological and genotyping results revealed that 29 of the cases belonged to four different outbreaks, whereas the remaining four cases were separate importations. The outbreaks were caused by two distinct variants of genotype $B_{3}$, genotype $D_{4}$ and D9, whereas genotype B3 (two variants) and D8 were detected in the four sporadic cases.

\section{Measles introduction with} secondary spread: outbreak 1

The highest number of cases $(n=18)$ was identified in the first outbreak that started on 19 January 2011 (week 3 ) in Oslo (Table), and ended week 12 (Figure 1). The first laboratory-confirmed case was an unvaccinated child $<2$ years of age from the Somali immigrant population. The child, who had relatives living in Ethiopia, developed classical measles symptoms 12 days after the arrival of family members from Ethiopia. The index case (not included in the study) was probably one of the visiting relatives, according to the symptoms described by the parents. During the first weeks of the outbreak, measles spread to unvaccinated children within the
Somali immigrant population living in the same area in Oslo (Old Oslo).

Steps to avoid secondary transmission were taken. The day after the first case was laboratory confirmed, healthcare workers (HCWs) visited families who had been in contact with the sick child and MMR vaccination was offered. Oral fluids were collected from potentially exposed children and tested on the following day. One new case was detected, and vaccination status of the contacts was obtained. All unvaccinated contacts were offered MMR. To prevent the spread, oral and written information was given to the Somali community immediately after the first two cases were laboratory confirmed. The information was also given in their native language.

Measles were confirmed in eight Somali children < 10 years of age. The remaining confirmed cases were Norwegian children $(n=6)$ and adults $(n=4)$ (Table) who were exposed in a healthcare setting. During the beginning of the outbreak, it became clear that rapid communication of information was important to increase awareness amongst HCWs. Updated bulletins were therefore sent to healthcare personnel by e-mail as well as posted on the NIPH's website.

Five of the six unvaccinated Norwegian children were exposed to measles in a waiting room at the emergency centre in Oslo. All, except one, were under the age when the first MMR dose is recommended. Only four of the 14 children were female. The four adult cases were

\section{FIGURE 1}

Distribution of laboratory-confirmed measles cases by date and week of symptom onset, Norway,

19 January-5 October $2011(n=33)$

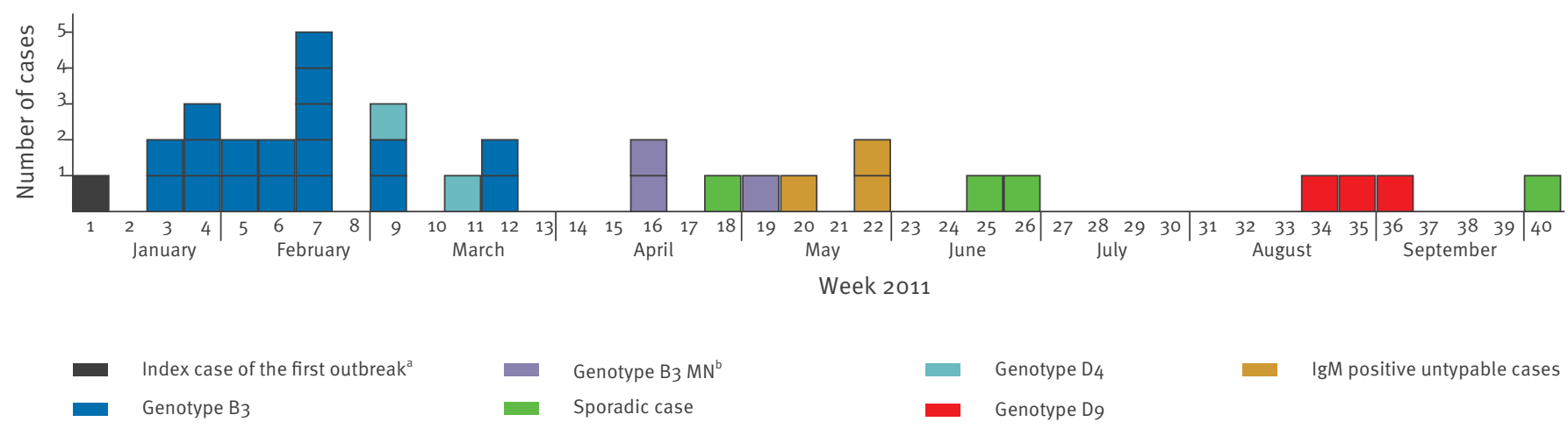

\footnotetext{
a The index case was a visiting relative of the first laboratory-confirmed case in the first outbreak. The index case had travelled to Norway
} from Ethiopia and was neither laboratory confirmed nor included in the study.

b Genotype B3 variants similar to the strains detected in Minnesota (MVs/Minnesota.USA/10.11/2 and MVs/Minnesota.USA/12). 
HCWs employed at a healthcare centre $(n=1)$ and children's ward at a hospital $(n=3)$. According to SYSVAK, two of the HCWs had been vaccinated twice with the $M M R$ vaccine in line with the national children vaccination programme [10], whereas one was not previously vaccinated against measles. No information was available regarding the last HCW. All HCWs at the children's ward of the hospital were offered a booster dose of MMR.

Epidemiological investigation demonstrated a link between all 18 cases involved in this outbreak (Table). Acute phase serum and/or oral fluid were obtained from 17 of the 18 cases, and specific anti-measles IgM antibodies were detected in all 18 cases with at least one of the ELISA assays used in the laboratory (Table).

Primary (PVF) and secondary vaccine failure (SVF) was seen in the two fully immunised HCWs, case 20 and 19 respectively. A weak IgM reaction was obtained in the acute phase oral fluid obtained from case 19, whereas the corresponding serum sample was IgM negative. High avidity IgG-antibodies (97\%) were detected in both acute phase- and convalescence serum samples in case 19 consistent with SVF. In case 20, measles infection was confirmed by detection of measles virus by PCR, IgM seroconversion and four-fold IgG increase between acute phase- and convalescence samples. An increase in avidity ratio was seen between acute phase serum (69\%) and convalescence serum (94\%) in case 20, consistent with PVF.

Measles infection was confirmed by PCR in 13 cases, including case 20. All the PCR positive samples were oral fluids collected between day one and day eight after the onset of symptoms, however, three of the acute phase oral fluids turned out to be PCR negative. All PCR positive samples were sequenced, and identical sequences revealing genotype $B_{3}$ were obtained (Figure 2). The similarity between the $\mathrm{B}_{3}$ strain detected in this outbreak and the WHO reference strain MVi/Ibadan NIE/97/1 (MeaNS) was 98.7\%, but differed only by one nt from another B3 variant (MVs/Nairobi. $\mathrm{KEN} / 41.05 / 1)$ detected in an outbreak in Kenya in 2005 (personal communication, Sheilagh Smit, 12 May 2011).

All cases had typical symptoms of measles including a generalised maculopapular erythematous rash, fever, cough, runny nose and red eyes. The two vaccinated HCWs although showing milder symptoms, clearly had measles infection. They had both been exposed to measles virus for a prolonged period during their duty. Only one of the children who were admitted to hospital developed severe measles pneumonia, the others were admitted due to dehydration and impaired general condition. In Norway, the threshold to hospitalise measles cases is low for isolation purposes.
Measles introduction with limited

spread: outbreaks 2, 3 and 4

During outbreak 1, genotyping of samples from two persons affected by measles yielded an identical geno-

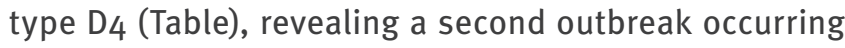
in parallel. The index case (case 15) in this outbreak 2 was a tourist from Spain who arrived in Oslo 16 February and fell ill 28 February (week 9) and the second case (case 18) occurred in Oslo two weeks later in an unvaccinated child $<2$ years of age (Table). The D4 variant detected in these two cases differed only by one nt from the D4 strain causing outbreaks among Irish travellers in the UK and Norway in 2007 (Figure 2) $[23,24]$. Epidemiological investigation did not identify a link between these two cases.

Outbreak 3 started on 19 April 2011 in Oslo (week 16). The index case (case 21) was an unvaccinated Somali child $<2$ years of age who got measles after a visit to Kenya. Measles was confirmed also between week 16 and 19 in three additional children; one child from eastern Europe (case 22), one unvaccinated Somali child < 2 years of age who contracted measles in Kenya (case 23) and one Norwegian child living in Oslo (case 24). Measles IgM antibodies were detected in acute phase serum and/or oral fluid in all four cases. Epidemiological investigation did not identify a link between these four cases, whereas genotyping revealed identical $\mathrm{B}_{3}$ strains (MVs/Oslo.NOR/16.11, MVs/Oslo.NOR/16.11/2 and MVs/Oslo.NOR/19.11) in three of the cases (case 21, 22 and 24) representing outbreak 3.

As shown in Figure 2, different variants of genotype $B_{3}$ caused outbreak 1 and 3 . The similarity between the $B_{3}$ variant detected in outbreak 3 and the WHO reference strain MVi/Ibadan NIE/97/1 was $97.6 \%$, but differed by only one to three nt from the B3 variant detected in the Somali community in Minneapolis (Minnesota) in late March 2011 (MVs/Minnesota.USA/10.11/2).

The B3 variant (MVs/Oslo.NOR/18.11) detected in case 23 was one nt different from the $B_{3}$ variant causing outbreak 3 and was therefore not included in the outbreak (Figure 2). In addition, three unvaccinated siblings developed measles in week 20 and 22. Measles was confirmed serologically by detection of IgM antibodies in serum and/or oral fluid. Although epidemiological investigation did not demonstrate a link between the siblings and the cases previously described in outbreak 3, they were most probably part of outbreak 3. One of them was from Oslo, whilst the two others resided just outside Oslo (Table).

Outbreak 4 started on 22 August (week 34) and the index case was an unvaccinated Norwegian child between two and 10 years-old. The child developed classical symptoms of measles shortly after a visit to south-east Asia. Measles was later confirmed by detection of measles IgM antibodies in serum and/or oral fluid as well as in two additional other unvaccinated children; a child < 2 years of age living in the same area 


\section{FIGURE 2}

Phylogenetic tree showing clusters of measles virus sequences derived from clinical samples of each measles case, Norway, $2011(\mathrm{n}=33))$

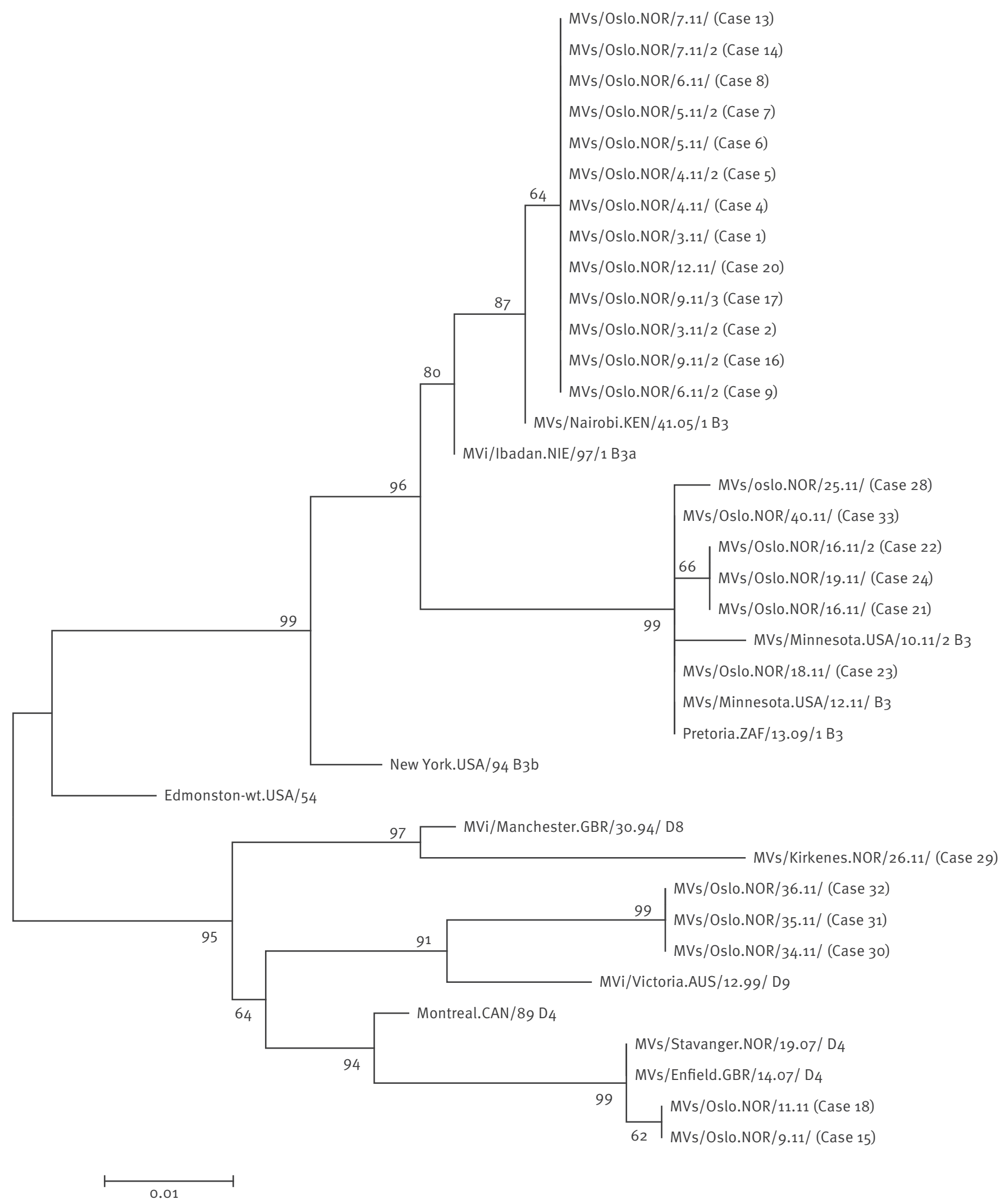

The numbers at the nodes are values obtained with the bootstrap test (1,000 replicates). 
(week 35) and a schoolmate of the index case (week 36). Genotyping revealed an identical genotype $D 9$ in all three cases (Figure 2), whereas epidemiological link was only identified between two of the cases.

\section{Measles introductions without}

\section{secondary spread}

Based on the epidemiological and molecular investigations, four of the measles cases in 2011 were assigned as sporadic importations (case 23, 28, 29 and 33) (Table). Genotyping revealed an identical B3 variant in case 23 (described in outbreak 3 ) and case 33 (Figure 2), also identical to a $B 3$ variant detected in Minnesota in 2011 (MVs/Minnesota.USA/12.11). Case 33 was an unvaccinated adult who contracted measles in Angola, Africa (week 40). A slightly different B3 variant (1 nt) was detected in an unvaccinated child (case 28) who contracted measles in Kenya and fell ill before arrival to Oslo (week 25). Measles genotype D8 was detected in an unvaccinated child (case 29) living in northern Norway, however, no epidemiological data or travel history was available. Measles was initially confirmed in all of these cases by detection of IgM antibodies in acute phase sample.

\section{Discussion}

This study describes the introduction of at least eight different measles viruses into Norway during the year 2011. We investigated a total of 33 measles cases, which could be grouped into four outbreaks and four sporadic cases. The measles virus genotypes detected during 2011 were D4, D9, D8 and four different sequence variants of genotype $B_{3}$ as shown in Figure 2. This is the largest number of measles cases reported within a single year since the large outbreak at Nesodden near Oslo in an anthroposophic community in 1997. Since then, only imported cases have been identified in Norway [12]. The situation seen in Norway in 2011, may thus reflect the increased number of measles cases and multistate outbreaks of measles that have been observed in European countries [2].

The largest outbreak in Norway started January 2011 with importation from Ethiopia and 18 people were infected during the following nine weeks. Genotyping showed that the outbreak was sustained by an identical B3 variant (Figure 2). Genotype B3 was the most frequently reported genotype from Africa to the WHO Global Sequence database during the period from 2007 to 2009, and was also found circulating in Malawi, Liberia and Mauritania in 2010 [8]. Genotype B3 has been associated with outbreaks in Kenya in 2005 [25], and a nearly identical B3 variant was detected in outbreak 1. Genotype B3 is currently regarded as an endemic genotype in most of the African continent, including Kenya and Ethiopia, and has been associated with importations from African countries to other parts of the world [25]. The index case in outbreak 1 was a family member living in Ethiopia, and the $B_{3}$ variant detected in this outbreak differed by only one nt from a B3 variant (MVs/Nairobi.KEN/41.05/1) causing outbreaks in Kenya in 2005.

Additionally three other genotype B3 variants were imported to Norway from Kenya during 2011, however only one of the variants resulted in a small outbreak 3. These different $B_{3}$ variants were either identical or one to three nt different from the $\mathrm{B}_{3}$ variants (MVs/Minnesota.USA/12.11 and MVs/Minnesota. USA/10.11/2) that caused outbreaks in the Somali community in Minnesota in 2011 (Figure 2). Epidemiological data did not identify a link between all cases infected with the slightly different $B_{3}$ variants, indicating that the strains were independent importations and showing how easily measles virus spreads between countries among susceptible individuals. However, one must bear in mind that only minor sequence differences were obtained.

Population immunity in Norway is generally sufficiently high to prevent sustained transmission of measles virus, and was probably the reason why further transmission of some of the imported strains did not develop. In addition, there was a lot of awareness among HCWs and the public due to the ongoing outbreaks, especially the first three, and local health authorities organised vaccination campaigns and provided information to the affected community. In spite of this, this study nevertheless shows that even in a country with a generally high MMR coverage, the measles virus can affect a group with low vaccine coverage and cause an outbreak affecting unvaccinated individuals both in and outside the group. The measles outbreaks gave an opportunity to investigate the reasons why parents choose not to vaccinate their children, and at the same time to disperse misbeliefs concerning MMR vaccination. Reasons for non-vaccination were mainly fear of side effects of the vaccine.

The results highlight the importance of genotyping in order to trace the source of infections, to distinguish sporadic cases from outbreak cases and to verify the end of an outbreak. For example, measles cases with the outbreak 1 genotype were not detected after week 12 , suggesting the end of this outbreak, while two measles cases subsequently occurring in week 16 were shown to be part of a new different outbreak (outbreak 3) involving a different genotype from that of outbreak 1.

The outbreaks also demonstrated that the measles virus was easily transmitted to unvaccinated individuals in healthcare facilities and emergency centres, which are separate centres located outside the hospitals. As seen in other studies $[26,27]$, the outbreaks affected mainly unvaccinated children $<2$ years of age (Table). Many of the affected children were under the age when the first MMR dose normally is given ( 15 month). This raised the question as to whether the age for administration of the first dose should be brought down to 12 months, however as eight of the cases were 
under 12 months of age, these would not have been avoided by lowering the age.

Measles infection was also demonstrated in four HCWs, two fully immunised, one unvaccinated and one with no information on vaccination status. Genotyping revealed an identical $\mathrm{B}_{3}$ variant in two of the $\mathrm{HCWs}$ (case 17 and case 20), and demonstrated that these two also became a source of transmission. The two fully immunised HCWs had, according to the national vaccination programme, received two doses of MMR vaccines during childhood and were therefore classified as primary and secondary vaccine failure (PVF and SVF). Diagnosis of SVF may be challenging, however, anti-measles IgM in oral fluid and high-avidity anti-measles IgG in serum samples were documented in the case with SVF (case 19). An assay for detection of measles plaque reduction neutralisation antibodies was not available. SVF cases with mild clinical course similar to the case reported in this study have been observed in several studies [28]. Such cases are regarded as less contagious than unvaccinated measles cases, as measles virus in these circumstances can be difficult to detect and transmission is limited. Waning of the measles antibody has been observed in cohorts of vaccinees 10 years after the second dose [29], and in the case of extended duration of measles virus exposure, previously immune individuals can develop infection [30].

The genotype $\mathrm{D}_{4}$ detected in this study differed only by one $\mathrm{nt}$ from the genotype D4 detected in Irish travellers in UK and Norway in 2007 (Figure 2) [24,2], indicating that a nearly identical D4 variant is still circulating in Europe. Genotype D4 has been associated with large numbers of cases and outbreaks in Europe the last years [5,31] and was detected in 24 countries in Europe during 2011 [2]. The index case in outbreak 2 fell ill 12 days after arrival in Oslo and was probably infected in Spain or during transit, however endemic circulation of closely related $\mathrm{D}_{4}$ variants makes it difficult to trace the transmission pathways.

The genotype D9 causing outbreak 4 was imported by the index case who had visited south-east Asia. Genotyping revealed identical sequences in two additional measles cases, although epidemiological link was only confirmed between the index case and a schoolmate. However, all three cases lived in the same area of Oslo. Measles has a high basic reproduction number $\left(R_{0}: 12-18\right)$ [32], and transmission is possible by infectious measles virus-containing respiratory droplets for up to two hours after the infectious individual has departed an area [33]. Genotype D9 has been associated with endemic transmission in several countries in Asia [8].

This study demonstrates the importance of obtaining an adequate sample for virological surveillance. Oral fluid is the preferred sample type for PCR examination and genotyping, and the chance of detecting measles virus is highest in the first week of the disease.
Acute phase oral fluid was obtained from the majority of cases (Table), and PCR was able to detect measles virus in oral fluid taken between day one and day eight from the onset of symptoms. In addition, as most of the cases in this study were small children, oral fluid is also easier to obtain. Although some cases with milder symptoms could have been missed, we do not believe that there were many missed opportunities in identifying the exposed individuals as samples are taken from patients showing any symptoms of measles. Nevertheless, there might been a few missed cases, especially ones with mild symptoms.

In conclusion, this study has shown that molecular analyses of measles virus detected in Norway in 2011 provided important information in order to track the transmission path, the origin of the infection, to distinguish sporadic cases from outbreak cases and confirm vaccine failure. Especially in countries nearing the measles elimination goal, molecular analysis is essential in verification of elimination and to monitor the impact of importations, which can cause limited outbreaks. For preventing such outbreaks, organising information and vaccination campaigns in the affected communities is important. In Norway, hospitalised children with rash illness are isolated but this measure is not in place for outpatient settings. Recommendations concerning the handling of suspected measles cases in outpatient settings are warranted in order to avoid the spread of measles within healthcare centres. The four cases among the HCWs emphasised that the coverage of MMR vaccination among healthcare personnel needs to be improved as, due to their type of work, HCWs can be particularly exposed to measles and, if infected, can potentially transmit the disease to patients. More studies are also needed to investigate the cause of the SVF, and the impact with regards to the measles elimination plan.

Acknowledgments

This study was financially supported by the Norwegian Institute of Public Health.

We thank the laboratory personnel at the virology laboratory, especially Hege Fremstad, for excellent technical assistance. 


\section{References}

1. World Health Organization (WHO). Measles. Geneva: WHO. [Accessed 26 Sep 2012]. Available from: http://www.who.int/ mediacentre/factsheets/fs286/en/

2. Centers for Disease Control and Prevention (CDC). Increased transmission and outbreaks of measles -- European Region, 2011. MMWR Morb Mortal Wkly Rep. 2011;60(47):1605-10.

3. Steffens I, Martin R, Lopalco P. Spotlight on measles 2010: Measles elimination in Europe -- a new commitment to meet the goal by 2015. Euro Surveill. 2010;15(50):pii=19749. Available from: http://www.eurosurveillance.org/ViewArticle. aspx?Articleld $=19749$

4. World Health Organization Regional Office for Europe (WHO Europe). Renewed commitment to elimination of measles and rubella and prevention of congenital rubella syndrome by 2015 and Sustained support for Polio-free status in the WHO European Region. WHO publication EUR/RC60/ R12. Copenhagen: WHO Europe; 13-16 Sep 2010. Available from: http://www.euro.who.int/_data/assets/pdf file/0016/122236/RC60_eRes12.pdf

5. Mankertz A, Mulders MN, Shulga S, Kremer JR, Brown KE, Santibanez S, et al. Molecular genotyping and epidemiology of measles virus transmission in the World Health Organization European Region, 2007-2009. J Infect Dis. 2011;204 Suppl 1:S335-42.

6. World Health Organization Regional Office for Europe (WHO Europe). Surveillance guidelines for measles, rubella and congenital rubella syndrome in the WHO European Region. WHO publication EUR/08/5082738. Copenhagen: WHO Europe; 2009. Available from: http://www.euro.who.int/_data/assets/ pdf_file/0018/79020/E93035.pdf

7. Brown KE, Mulders MN, Freymuth F, Santibanez S, Mosquera $M M$, Cordey S, et al. Appearance of a novel measles $\mathrm{G}_{3}$ strain in multiple European countries within a two month period, 2010. Euro Surveill. 2011;16(17):pii=19852. Available from: http://www.eurosurveillance.org/ViewArticle. aspx?Articleld $=19852$

8. Rota PA, Brown K, Mankertz A, Santibanez S, Shulga S, Muller CP, et al. Global distribution of measles genotypes and measles molecular epidemiology. J Infect Dis. 2011;204 Suppl 1:S514-23.

9. World Health Organization Regional Office for Europe (WHO Europe). Eliminating measles and rubella and preventing congenital rubella infection: WHO European region strategic Plan 2005-2010. Copenhagen: WHO Europe; 2005. Available from: http://www.euro.who.int/_data/assets/pdf file/oo08/79028/E87772.pdf

10. Norwegian Institute of Public Health (NIPH). Nasjonalt vaksinasjonsregister (SYSVAK). [National vaccine register-SYSVAK].Oslo: NIPH. [Accessed $20 \mathrm{Apr}$ 2012]. Norwegian. Available from: http://www.fhi.no/eway/ default.aspx?pid=233\&trg=MainArea 5661\&MainAr ea $5661=6068: 0: 17,4297: 1: 0: 0::: 0: 0$

11. Norwegian Institute of Public Health (NIPH). Smittevernboka; Meslinger (morbilli) [Infection Control Manual; Measles (morbilli)]. [Accessed o6 Dec 2012]. Available from: http:// www.fhi.no/eway/default.aspx?pid=233\&trg=MainLeft_6 039\&MainArea_5661=6039:0:15,5078:1:0:0:::0:0\&MainLe $\mathrm{ft} 6039=6041: 82822:: 1: 6043: 80:: 0: 0$

12. Norwegian Surveillance System for Communicable Diseases (MSIS). [Accessed 20 Apr 2012]. Available from: www.msis.no

13. Løvoll $\varnothing$, Vonen L, Vevatne T, Sagvik E, Vainio K, Sandbu S, et al. An outbreak of measles among a travelling community from England in Norway: a preliminary report. Euro Surveill. 2007;12(21):pii=3198. Available from: http://www. eurosurveillance.org/ViewArticle.aspx?Articleld =3198

14. Schmid D, Holzmann H, Abele S, Kasper S, König S, Meusburger S, et al. An ongoing multi-state outbreak of measles linked to non-immune anthroposophic communities in Austria, Germany, and Norway, March-April 2008. Euro Surveill. 2008;13(16): pii=18838. Available from: http://www. eurosurveillance.org/ViewArticle.aspx?Articleld =18838

15. Vainio K, Rønning K, Steen TW, Arnesen TM, Anestad G, Dudman S. Ongoing outbreak of measles in Oslo, Norway, January-February 2011. Euro Surveill. 2011;16(8):pii=19804. Available from: http://www.eurosurveillance.org/ViewArticle. aspx?Articleld $=19804$

16. World Health Organization (WHO). WHO recommended surveillance standard of measles. Geneva: WHO. [Accessed 20 Apr 2012]. Available from: http://www.who.int/ immunization_monitoring/diseases/measles_surveillance/en/

17. World Health Organization (WHO). New genotype of measles virus and update on global distribution of measles genotypes. Wkly Epidemiol Rec. 2005;80(40):347-51.
18. 18.Thompson JD, Gibson TJ, Plewniak F, Jeanmougin F, Higgins DG. The CLUSTAL $X$ windows interface: flexible strategies for multiple sequence alignment aided by quality analysis tools. Nucleic Acids Res. 1997;25(24):4876-82.

19. Tamura K, Peterson D, Peterson N, Stecher G, Nei M, Kumar S. MEGA5: molecular evolutionary genetics analysis using maximum likelihood, evolutionary distance, and maximum parsimony methods. Mol Biol Evol. 2011;28(10):2731-9.

20. Update of the nomenclature for describing the genetic characteristics of wild-type measles viruses: new genotypes and reference strains. Wkly Epidemiol Rec. 2003;78(27):229-32.

21. Measles virus nomenclature update: 2012 . Wkly Epidemiol Rec. 2012;87(9):73-81.

22. Gnaneshan S, Brown KE, Green J, Brown DW. On-line global/ WHO-European regional measles nucleotide surveillance. Euro Surveill. 2008;13(19):pii=18861. Available from: http://www. eurosurveillance.org/ViewArticle.aspx?Articleld=18861

23. Cohuet S, Morgan O, Bukasa A, Heathcock R, White J, Brown K, et al. Outbreak of measles among Irish Travellers in England, March to May 2007. Euro Surveill. 2007;12(24):pii=3216. Available from: http://www.eurosurveillance.org/ViewArticle. aspx?Articleld $=3216$

24. Løvoll $\varnothing$, Vonen L, Nordbø SA, Vevatne T, Sagvik E, Vainio $\mathrm{K}$, et al. Outbreak of measles among Irish Travellers in Norway: an update. Euro Surveill. 2007;12(24): pii=3217. Available from: http://www.eurosurveillance.org/ViewArticle. aspx?Articleld $=3217$

25. Rota J, Lowe L, Rota P, Bellini W, Redd S, Dayan G, et al. Identical genotype $B_{3}$ sequences from measles patients in 4 countries, 2005. Emerg Infect Dis. 2006;12(11):1779-81.

26. Stanescu A, Janta D, Lupulescu E, Necula G, Lazar M, Molnar G, et al. Ongoing measles outbreak in Romania, 2011. Euro Surveill. 2011;16(31):pii=19932. Available from: http://www. eurosurveillance.org/ViewArticle.aspx?Articleld=19932

27. Filia A, Tavilla A, Bella A, Magurano F, Ansaldi F, Chironna $M$, et al. Measles in Italy, July 2009 to September 2010. Euro Surveill. 2011;16(29):pii=19925. Available from: http://www. eurosurveillance.org/ViewArticle.aspx?Articleld=19925

28. Hickman CJ, Hyde TB, Sowers SB, Mercader S, McGrew M, Williams NJ, et al. Laboratory characterization of measles virus infection in previously vaccinated and unvaccinated individuals. J Infect Dis. 2011;204 Suppl 1:S549-58.

29. LeBaron CW, Beeler J, Sullivan BJ, Forghani B, Bi D, Beck C, et al.Persistence of measles antibodies after 2 doses of measles vaccine in a postelimination environment. Arch Pediatr Adolesc Med. 2007;161(3):294-301.

30. Krugman S, Giles JP, Friedman H, Stone S. Studies on immunity to measles. J Pediatr. 1965;66:471-88.

31. Mankertz A, Mihneva Z, Gold H, Baumgarte S, Baillot A, Helble $\mathrm{R}$, et al. Spread of measles virus D4-Hamburg, Europe, 20082011. Emerg Infect Dis. 2011;17(8):1396-401.

32. Wadl M, Siedler A, Krämer W, Haindl ME, Gebrande S, KrennLanzl I, et al. Measles transmission from an anthroposophic community to the general population, Germany 2008. BMC Public Health. 2011;11:474.

33. Biellik RJ, Clements CJ. [Strategies for minimizing nosocomial transmission of measles]. Rev Panam Salud Publica. 1998;4(5):350-7. Spanish. 